\title{
LUDO DAS LIGAÇÕES QUÍMICAS: UM JOGO DIDÁTICO NO ENSINO DE QUUIMICA
}

\section{LUDO OF THE CHEMICAL LINKS: A TEACHING GAME IN CHEMISTRY}

\section{Autores:}

${ }^{1}$ Ayrton Matheus da Silva Nascimento

Licenciado em Química e professor de Química, Vitória de Santo Antão, Pernambuco - Brasil.

${ }^{2}$ Welly Evilly da Silva Vieira

Licencianda em Química, IFPE - campus Vitória de Santo Antão, Pernambuco - Brasil.

${ }^{3}$ Natália Kelly da Silva Araújo

Licencianda em Química, IFPE - campus Vitória de Santo Antão, Pernambuco - Brasil.

${ }^{4}$ Higor Diego Farias de Melo

Licenciando em Química, IFPE - campus Vitória de Santo Antão, Pernambuco - Brasil

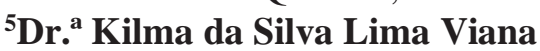

Doutora em Ensino de Ciências (Física e Química), Professora do IFPE - campus Vitória, Presidente do Instituto Internacional Despertando Vocações - IIDV, Pernambuco - Brasil.

Orientadora:

Dr. ${ }^{a}$ Kilma da Silva Lima Viana

Coorientador:

Ayrton Matheus da Silva Nascimento

Contato do autor principal:

ayrthon.matheus@gmail.com

Propriedade Terra Preta, s/n, Zona Rural - Vitória de Santo Antão - Pernambuco, Brasil CEP: 55608-903. 


\title{
LUDO DAS LIGAÇÕES QUÍMICAS: UM JOGO DIDÁTICO NO ENSINO DE QUÍMICA
}

\author{
LUDO OF THE CHEMICAL LINKS: A TEACHING GAME IN CHEMISTRY
}

${ }^{1}$ Ayrton Matheus da Silva Nascimento; ${ }^{2}$ Welly Evilly da Silva Vieira; ${ }^{3}$ Natália Kelly da Silva Araújo;

${ }^{4}$ Higor Diego Farias de Melo; ${ }^{5}$ Dr. ${ }^{a}$ Kilma da Silva Lima Viana

\begin{abstract}
Resumo: Esse artigo apresenta os resultados iniciais de uma pesquisa desenvolvida na disciplina de Prática Profissional (IV) do Curso de Licenciatura em Química do Instituto Federal de Pernambuco IFPE Campus Vitória, onde a disciplina tem o objetivo de estudar, analisar e elaborar recursos didáticos, dentre esses, o jogo didático irá ser utilizado em nossa pesquisa. O presente estudo aborda o desenvolvimento, aplicação e a avaliação de um jogo didático com a utilização do Ciclo da Experiência Kellyana (CEK) para o ensino de química geral no ensino médio, no conteúdo de Ligações Química (Ligações covalentes) por meio de situação em que os estudantes consigam compreender e diferenciar os compostos covalentes, formar as estruturas e aprender a regra do octeto. Analisando estas situações, este trabalho tem a intenção de abordar uma intervenção com um Jogo Didático intitulado: Ludo das Ligações Químicas, com 38 (trinta e oito) estudantes de uma turma de primeiro ano do IFPE - Campus VSA. Para isso, foi aplicado o jogo com os estudantes e questionários (Q1 e Q2) sobre a observação e vivência do CEK. Como objetivos atingidos, foi analisado o quanto o jogo auxiliou na compreensão dos conteúdos, pois os estudantes compreenderam as ligações covalentes de forma mais divertida e atrativa, precipuamente com relação à identificação dos compostos covalentes e suas respectivas estruturas, dessa forma compreendendo a regra do octeto. Além disso, pudemos identificar a partir dos questionários que os estudantes aprimoraram suas hipóteses iniciais acerca do conteúdo que foi abordado no CEK e solidificaram seus conhecimentos.
\end{abstract}

Palavras-chave: Ciclo da Experiência Kellyana (CEK), Ligações Covalentes, Lúdico.

\begin{abstract}
This article presents the initial results of a research developed in the discipline of Professional Practice (IV) of the Degree in Chemistry of the Federal Institute of Pernambuco - IFPE Campus Vitória, where the discipline aims to study, analyze and elaborate didactic resources, among These, the didactic game will be used in our research. The present study deals with the development, application and evaluation of a didactic game using the Kellyana Experiment Cycle (CEK) for the teaching of general chemistry in high school, in the content of Chemical Bonds (covalent bonds) through a situation in That students can understand and differentiate covalent compounds, form structures, and learn the octet rule. Analyzing these situations, this work intends to approach an intervention with a Didactic Game titled: Ludo of the Chemical Links, with 38 (thirty eight) students of a first class class of IFPE - VSA Campus. For that, the game was applied with the students and questionnaires (Q1 and Q2) about the observation and experience of the CEK. As objectives reached, it was analyzed how much the game aided in the comprehension of the contents, since the students understood the covalent bonds in a more fun and attractive way, precipitously with respect to the identification of the covalent compounds and their respective structures, of this form comprising the octet rule. In addition, we were able to identify from the questionnaires that the students improved their initial hypotheses about the content that was approached in the CEK and solidified their knowledge.
\end{abstract}

Keywords: Experience Cycle Kellyana (CEK), Covalent Bonds, Playful.

\section{INTRODUÇÃO}

Influenciados pelos teóricos da educação, como, Luck (2010), Libânio (1994) e Perrenoud (2000), tencionamos trabalhar na perspectiva de superar a fragmentação do ensino, principalmente do ensino de Química. Desse modo, objetiva-se a formação integral dos envolvidos, pois, é preciso que os profissionais formadores de formadores, sejam capazes de 
enfrentar problemas complexos e adquirirem a capacidade de trabalhar com criatividade.

Percebe-se então, a necessidade de construir ambientes de conhecimentos extracurriculares, como por exemplos, os recursos didáticos alternativos para o ensino de Química. Estes, por sua vez surgem como uma oportunidade de diálogo, interdisciplinaridade e principalmente a articulação entre a teoria e a prática docente.

Diante deste cenário, os Jogos Didáticos atuam como uma alternativa de refúgio de uma prática tradicional tão predominante em sala de aula, pois é uma abordagem que contribui de maneira a render mais, no ensino-aprendizagem dos alunos. É muito importante garantir novas práticas de ensino para os discentes, porque os mesmos acham a Química uma disciplina monótona e maçante, segundo estudo na área. Sendo assim, a Química como Ciência se torna desestimulante, pelo fato dos docentes não aproveitarem, ou seja, não explorarem de fato o que a matéria proporciona.

Analisando estas situações, este trabalho tem a intenção de abordar uma intervenção com um Jogo Didático intitulado: Ludo das Ligações Químicas, com os estudantes de uma turma de primeiro ano de uma escola de rede Pública Federal do estado de Pernambuco, o Instituto Federal de Pernambuco (IFPE - Campus Vitória de Santo Antão).

\section{FUNDAMENTAÇÃO TEÓRICA}

Muitas das dificuldades enfrentadas pelos alunos do Ensino Médio no aprendizado de Química estão diretamente relacionadas com o método de ensino utilizado pelos professores, que na sua maioria usa metodologias obsoletas e pouco dinâmicas.

Segundo Freitas (2007) os materiais didáticos têm a função de dinamizar as aulas e, com isso, aguçar a curiosidade do aluno, despertando a sua atenção para o que será tratado naquele momento, uma vez que as mensagens que são passadas não são somente verbais, mas abarcam sons, cores, formas e sensações, entre outros.

É neste sentido que conseguimos sair da aula expositiva monótona e conseguimos um elo entre o professor e o aluno. Vê-se nesta ideia a importância de materiais que auxiliem na construção do conhecimento pelo aluno e que ajudem ao professor na explanação dos conteúdos.

$\mathrm{Na}$ maioria das escolas tem-se dado maior ênfase à transmissão de conteúdos e à memorização de fatos, símbolos, nomes, fórmulas, deixando de lado a construção do conhecimento científico dos alunos e a desvinculação entre o conhecimento químico e o cotidiano. 
Jogos bem elaborados e explorados podem ser vistos como uma estratégia de ensino, podendo atingir diferentes objetivos que variam desde o simples treinamento, até a construção de um determinado conhecimento, afirma Lara (2004). Para que os jogos produzam os efeitos desejados é preciso que sejam, de certa forma, bem elaborados, e dirigidos pelos educadores de forma sucinta.

Segundo Miranda (2001), mediante o jogo didático, vários objetivos podem ser atingidos, relacionados à cognição (desenvolvimento da inteligência e da personalidade, fundamentais para a construção de conhecimentos); afeição (desenvolvimento da sensibilidade e da estima e atuação no sentido de estreitar laços de amizade e afetividade); socialização (simulação de vida em grupo); motivação (envolvimento da ação, do desafio e mobilização da curiosidade) e criatividade.

Ultimamente, os jogos didáticos têm ganhado espaço no ambiente escolar, e tem sido como aparelho motivador para a aprendizagem de conhecimentos químicos, à medida que propõe estímulo ao interesse do estudante. Se, por algum meio, o jogo ajuda o alunado a construir novas formas de pensamento, desenvolvendo e enriquecendo a construção de um assunto abordado, por outro lado, também para o professor, o jogo o leva à condição de transportador, estimulador e avaliador da aprendizagem. As propostas de jogos didáticos no ensino, já vem há décadas, não apenas na área de química como em outras áreas do conhecimento.

A utilização de jogos didáticos no Ensino de Química é um instrumento pedagógico que ganha visibilidade nas aulas, tornando mais atrativas e divertidas na forma de aprender e tornando uma disciplina agradável e útil (NASCIMENTO et al., 2015).

É importante ressaltar a importância do jogo que vem crescendo de maneira piloto nos últimos tempos, percebemos o aumentando quantitativo de artigos de jogos em diversas áreas do conhecimento, o jogo vem possibilitando uma aula mais atrativa tanto para o professor quanto o aluno, possibilitando a assimilação do conteúdo para os alunos com facilidade, e ao mesmo tempo ajudando ao professor a variar no uso desses recursos.

Também deve ser uma preocupação constante do professor como forma de considerar a heterogeneidade da turma, tornando assim a aprendizagem algo significativo para o aluno (SILVA et al., 2012). Isso porque a pluralidade de conhecimento é um componente marcante e vigente em nossa sociedade como uma metodologia que visa mudar a forma de explicar o conteúdo onde os alunos se divirtam e aprendam em sala de aula.

De acordo com (KISHIMOTO, 1996). O jogo para se considerar educativo tem que ter um equilíbrio entre duas variáveis: a lúdica e a educativa (KISHIMOTO, 1996). 
Os jogos educativos devem conciliar a liberdade característica dos jogos com a orientação própria dos processos educativos, já que a educação é tida como uma atividade séria e controlada, enquanto que jogar lembra diversão ou simplesmente brincar. Entretanto, a validade do jogo como instrumento que promova aprendizagem deve considerar que jogos no ensino são atividades controladas pelo professor, tornando-se atividades sérias e empenhadas com a aprendizagem. Isso não significa dizer que o jogo no ensino perde o seu caráter lúdico e a sua liberdade característica. No entanto, o jogo não deve ser utilizado ao acaso, mas visto como uma das atividades dentro de uma sequência definida de aprendizagens e um meio a serem usados para se alcançar determinados objetivos educacionais. (NASCIMENTO et al., 2014, p.1)

Para Campos e col. (2003), a aprendizagem significativa de conhecimentos torna-se mais fácil quando é apresentada em forma de atividade lúdica, pois os alunos ficam motivados e já predispostos a aprender quando recebem o conhecimento de forma mais interativa e divertida. Assim, os jogos podem ser considerados como uma alternativa viável, que podem vir a preencher muitas lacunas deixadas pelo processo de transmissão de informação, favorecendo a construção do conhecimento pelos próprios alunos. Estas autoras contribuem também para pensarmos que a função educativa do jogo possa se mostrar eficaz, de modo a favorecer aquisição e retenção de conhecimento, em clima de alegria e prazer, tornando-se uma importante estratégia para o ensino aprendizagem de conceitos complexos.

O uso do jogo no ambiente educacional apresenta características importantíssimas que contribuem para o processo de aprendizagem dos estudantes:

O jogo como promotor de aprendizagem e do desenvolvimento passa a ser considerado nas práticas escolares como aliado importante para o ensino, já que coloca o aluno diante de situações lúdicas. O jogo pode ser uma boa estratégia para aproximá-lo dos conteúdos culturais a serem vinculados na escola. (KISHIMOTO, 2003, p.13)

Segundo Santana (2008), o lúdico também pode contribuir para o aprendizado, pois além de ser prazeroso para o aluno, é a interpretação do contexto sócio histórico refletido na cultura, agindo como um mediador da aprendizagem, cooperando significativamente para o processo de construção do conhecimento do aluno.

Nesse sentido, os jogos são uma alternativa viável e interessante para aprimorar as relações entre professor - aluno - conhecimento, reconhecendo que estes podem proporcionar ao indivíduo um ambiente agradável, motivador, prazeroso e rico em possibilidades, que torna mais simples a aprendizagem de várias habilidades. Outra importante vantagem no uso de atividades lúdicas é a tendência em motivar o aluno a participar espontaneamente na aula. 
Acrescentam-se a isso, o auxílio do caráter lúdico no desenvolvimento da cooperação, da socialização e das relações afetivas, e a possibilidade de utilizar jogos didáticos, de modo a auxiliar os alunos na construção do conhecimento em qualquer área (Pedroso, 2009).

A Teoria dos Construtos Pessoais desenvolvida por George Kelly foi publicada em 1955, baseada numa filosofia de construção do conhecimento, chamada por ele de Alternativismo Construtivo. De acordo com essa visão, as pessoas constroem modelos provisórios para compreenderem a si mesma, os fenômenos ao seu redor, predizer e controlar eventos futuros. Esses modelos racionais são avaliados por critérios pessoais e alterados de acordo com os resultados dessa avaliação (BASTOS, 1992).

Segundo Kelly (1963) ao longo das várias tentativas de lidar com o evento, ela muda sua estrutura cognitiva para compreender melhor suas experiências, semelhante ao cientista que utiliza o método experimental para ajustar suas teorias. Essas construções pessoais são hipóteses de trabalho que se confronta com as experiências; estão sujeitas a constante revisão e recolocação. Ao contrastar as previsões antecipatórias com os acontecimentos, produz-se uma evolução progressiva de tais previsões. O processo de aprendizagem das pessoas ocorre segundo o Ciclo da Experiência Kellyana, composto de cinco etapas: Antecipação, Investimento, Encontro, Confirmação ou desconfirmação, e revisão construtiva (BASTOS 1992). Abaixo mostra a definição de cada uma das etapas proposto por George Kelly.

\section{Quadro 01: Etapas do Ciclo da Experiência Kellyana (CEK) (Fonte: Própria)}

\begin{tabular}{|c|c|}
\hline Etapas & O que ocorre \\
\hline $1^{\text {a }}$ Etapa: Antecipação & $\begin{array}{l}\text { Nesta etapa a pessoa usa os construtos que possui no seu } \\
\text { sistema de construção e tenta antecipar um evento que } \\
\text { está prestes a acontecer; }\end{array}$ \\
\hline $2^{\text {a }}$ Etapa: Investimento & $\begin{array}{l}\text { Nessa ordem ela se prepara para se encontrar com o } \\
\text { evento, momento esse de melhorar a construção da } \\
\text { réplica através da introdução de novos saberes; }\end{array}$ \\
\hline $3^{\text {a }}$ Etapa: Encontro & $\begin{array}{l}\text { Essa etapa é caracterizada pelo momento específico no } \\
\text { qual vai se deparar com o evento que antecipou; }\end{array}$ \\
\hline $\begin{array}{l}4^{\text {a }} \text { Etapa: Confirmação } \\
\text { e Desconfirmação }\end{array}$ & $\begin{array}{l}\text { Ela confirma ou desconfirma suas hipóteses iniciais } \\
\text { através da vivência no evento; }\end{array}$ \\
\hline $\begin{array}{l}\text { 5 }^{\text {a }} \text { Etapa: Revisão } \\
\text { Construtiva }\end{array}$ & $\begin{array}{l}\text { Para finalizar o ciclo, a pessoa é levada a reconstruir } \\
\text { seus construtos. }\end{array}$ \\
\hline
\end{tabular}




\section{METODOLOGIA}

Esta pesquisa apresenta natureza qualiquantitativa, pois visa compreender o processo em relação à aplicação do Jogo, bem como ao levantamento estatístico dos dados. Esta por sua vez, apresenta aspectos de pesquisa-ação, visto que, possibilita às participantes condições de investigar sua própria prática de uma forma crítica e reflexiva.

\section{Caracterização do Campo e dos Sujeitos de Pesquisa}

A pesquisa foi realizada em uma escola de rede Pública Federal no Instituto Federal de Pernambuco (IFPE) - Campus Vitória de Santo Antão. Os sujeitos foram 38 (trinta e outo) alunos que estudam o primeiro ano do Ensino Médio da escola supracitada. Esta intervenção teve como foco a disciplina de Química, uma vez que o Jogo Didático trabalha um conteúdo específico desta área: Ligações Químicas, mais precisamente as Ligações Covalentes.

\section{Instrumentos de Pesquisa}

Foram utilizados como instrumento de pesquisa dois questionários $\left(\mathrm{Q}_{1}\right.$ e $\left.\mathrm{Q}_{2}\right)$, onde o $\mathrm{Q}_{1}$ é um questionário diagnóstico que serve como sondagem referente ao conteúdo de Ligações Químicas e o $\mathrm{Q}_{2}$ é o questionário após a intervenção com o jogo, observação e registro da vivência como base metodológica o CEK (Ciclo da Experiência Kellyana) o qual é fundamentado na Teoria dos Construtos Pessoais de George Kelly (1963). Todos os sujeitos assinaram um termo de consentimento livre e esclarecido (TCLE).

\section{Aplicação do CEK (Ciclo da Experiência Kellyana) - "Ludo das Ligações Químicas"}

A abordagem deste jogo foi feita a partir das $\mathbf{0 5}$ (cinco) etapas do Ciclo da Experiência Kellyana - CEK:

- $\quad 1^{a}$ Etapa - Antecipação: Neste momento, foram levantados os conhecimentos prévios dos estudantes sobre o conteúdo: Ligação Covalente, e consequentemente à aplicação do Questionário $\left(\mathrm{Q}_{1}\right)$ que continha 05 (cinco) perguntas, sendo que a primeira questionava os estudantes a respeito de sua concepção sobre a disciplina de Química, a segunda se propôs, a saber, o julgamento dos discentes em relação aos jogos didáticos no ensino de Química, por fim, as três últimas questões se referem ao conteúdo propriamente dito.

- $\quad 2^{\mathbf{o}}$ Etapa - Investimento: Nesse momento foi apresentada uma aula dialogada por meio de slides sobre o assunto, introduzimos alguns conceitos básicos referentes ao respectivo 
tema, como por exemplo, a Regra do Octeto, bem como exceções a esta regra, princípios para a estabilidade, como se dá o compartilhamento de elétrons e de que forma os mesmos se relacionam com os tipos de ligações formadas. Este momento tem o propósito de fazer com que os discentes possam construir bases teóricas para em seguida realizar o jogo.

- $\quad 3^{\text {a }}$ Etapa - Encontro: Nesse momento, foi apresentado aos estudantes à realização e aplicação do jogo "Ludo das Ligações Químicas".

- $\quad 4^{a}$ Etapa - Confirmação ou Desconfirmação: Os estudantes por sua vez, confirmaram ou desconfirmaram se suas hipóteses iniciais condisseram com o Jogo aplicado e com a aula dialogada.

- $\quad 5^{\text {a }}$ Etapa - Revisão Construtiva: Nesta etapa os alunos são levados a refletir sobre a vivência da intervenção. Para o fechamento desse ciclo, foi aplicado um segundo questionário de abordagem qualiquantitativa a respeito contribuições do Jogo para a aprendizagem do conteúdo específico: Ligação Covalente.

\section{RESULTADOS E DISCUSSÃO}

\section{Ludo das Ligações Químicas}

O Ludo das Ligações Química é um jogo adaptado do jogo "Ludo" e inserido o conteúdo das Ligações Química como mostra a figura 03. Com esse jogo, os estudantes terão a oportunidade de entender e compreender em principal as "Ligações Covalentes", com seus exemplos e estruturas de Lewis. Para estudos e elaboração desse recurso didático foi utilizado como fonte de consulta o estudo de Fonseca (2012).

Algumas discussões sobre Ligações Covalentes são vistas no estudo de Fonseca (2012) que: "Dois átomos com alta eletronegatividade estabelecem uma ligação química compartilhando seus elétrons mais externos (de valência). O compartilhamento de pares de elétrons de valência é o que caracteriza a chamada ligação covalente".

Figura 02: Esquema da Ligação Covalente. Fonte: Fonseca (2012)

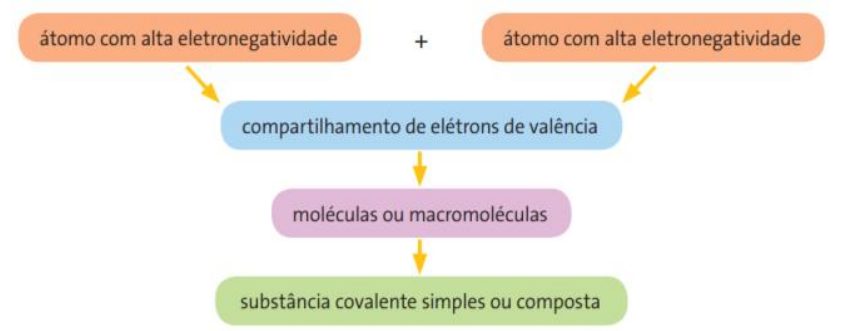




\section{Material}

- Papel Cartão A4;

- 01 Dado;
- 01 Envelope de cada cor;

- 04 botões de cada cor;

\section{Regras do Jogo:}

- Ludo é um jogo bastante atrativo para os adolescentes e jovens, desperta a forma de agir e pensar durante as estratégicas do tabuleiro, pode jogar de dois a quatro participantes;

- Cada um escolhe uma Base Química (BQ) que é representada por 04 cores, cada base tem uma Torre Química (TQ) e o objetivo é levá-la até a Zona Final, no meio do tabuleiro;

- O Ludo é jogado com um dado comum de seis faces. Cada participante (Rei da Base) joga o dado na sua vez, apenas tirando 01 ou 06 pode-se tirar a peça da base e posicionála no ponto de partida; resultado 06 dá direito a jogar mais uma vez, fazendo a peça andar o número de casas conforme o resultado;

- Para chegar ao fim do jogo, a TQ precisa percorrer uma volta no tabuleiro e entrar na Área de Segurança (onde ficará imune de ondas de perguntas);

- Cada base tem seu ponto de partida e a TQ percorre as casas no sentido horário. Durante o trajeto até a Zona Final tem algumas "Casas de Questões-(CQ)" como mostra a figura 02, que apresenta perguntas referentes ao conteúdo proposto pelo jogo, durante o perímetro, cada BQ colorida apresenta $04 \mathrm{CQ}$ (ressaltando que as casas que tem o símbolo de uma pergunta, simboliza “Área Livre”, ou seja, nesta casa o jogador estará “imune"), se parar em algumas CQ, o Rei da base colorida faz a pergunta referente à cor da área que parou, por exemplo, o jogador da área azul parou em uma CQ da área amarela, então, o jogador da área amarela pegará uma pergunta do envelope amarelo e fará ao respectivo jogador;

- Casa de Questão (CQ) - São cartas com perguntas referentes ao conteúdo de Ligações Químicas, mais precisamente "Ligação Covalente" onde cada Rei da Base ficará com questões referente ao conteúdo, apresentando perguntas e respostas;

- Durante o percurso, caso uma peça caia numa casa ocupada por outra adversária, esta última deve retornar à base, logo não é permitido mais do que uma peça em cada casa, isso é o chamado "comer" (principalmente no Brasil). É proibido "comer" o adversário que está na casa de saída. As peças apenas estarão livres desse ataque adversário após entrarem em sua respectiva Área de Segurança. Ao entrar na Área de Segurança 
(lembrando que cada TQ só pode entrar na Zona Final se concluir o percurso), precisa tirar o número exato de casas restantes no lance do dado, caso o jogador tire um resultado maior, sua TQ "bate e volta", ou seja, avança para a zona final e retrocede ao excedente de casas.

Figura 02: Modelo das Perguntas do Ludo das Ligações Químicas

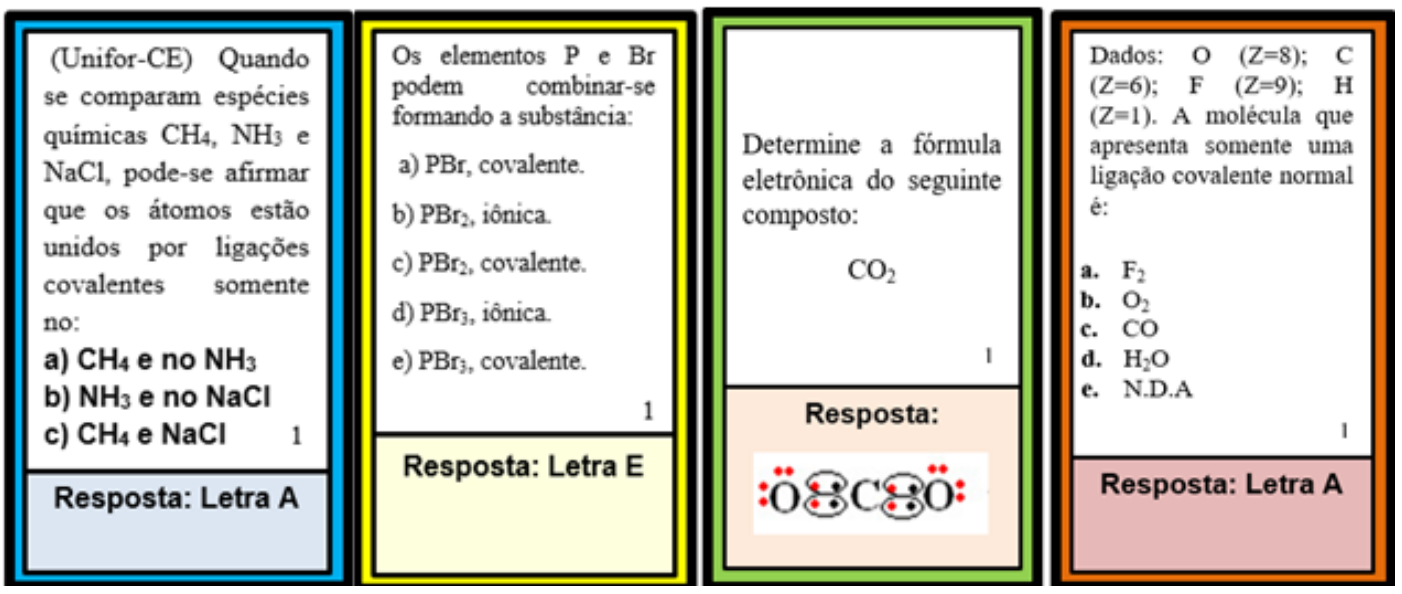

Figura 03: Modelo do Ludo das Ligações Químicas (Fonte: Própria)

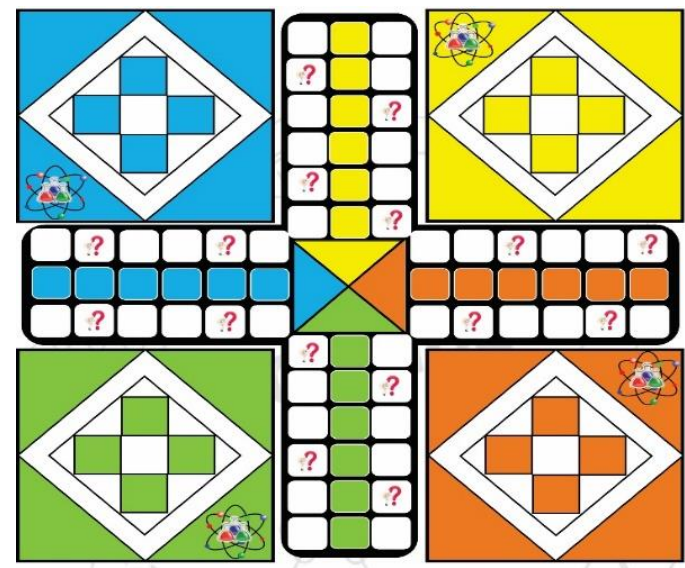

(B)(B)(D) (B)

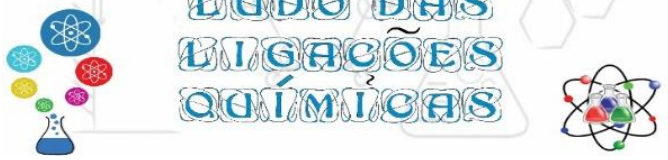

\section{Observação e Vivência do Ciclo da Experiência Kellyana (CEK)}

\section{Primeira Etapa do Ciclo da Experiência - (Antecipação)}

De acordo com o que já foi visto, é perceptível a importância de novos meios de ensino, como exemplo os jogos didáticos para construir um aprendizado mais elaborado e facilitador, desta maneira os alunos passam a se envolver com o novo e colaborando para com novas propostas relacionadas no ensino da química, esta que por sua vez é considerada uma "ciência 
dura" e com um nível de rejeição entre os discentes, segundo pesquisas.

Nesse momento foi iniciado o Ciclo, no qual antes de realizar o jogo "Ludo das Ligações Químicas”, foi aplicado um questionário diagnóstico $\left(\mathrm{Q}_{1}\right)$ que tinha por interesse de saber a relação da Química e os alunos, ou seja, se os estudantes observam a disciplina como uma barreira, considerando-a muito difícil de entender, ou se é uma área de importante contribuição para o cotidiano, e a contribuição das discussões de sala de aula aperfeiçoam a aprendizagem. Sendo assim, foram obtidos os seguintes dados:

Pergunta 01 (P1): Como você ver a disciplina de Química?

Figura 04: Resposta da $P_{1}$ antes da intervenção (Fonte: Própria)

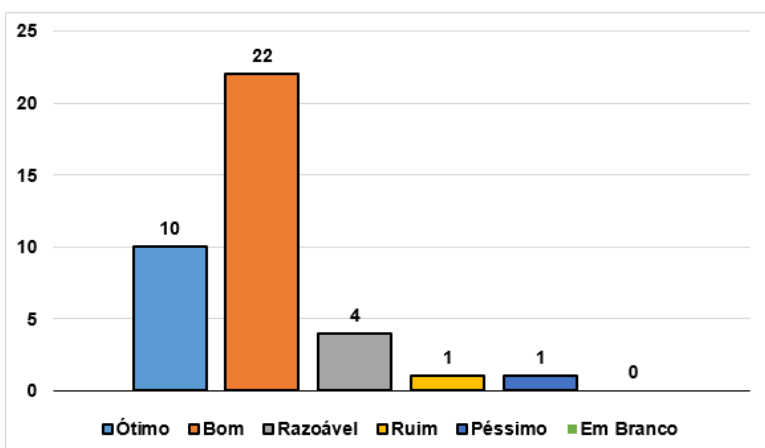

Como mostra a figura 04 , os resultados da primeira pergunta $\left(\mathrm{P}_{1}\right)$, foi possível perceber que os alunos consideram a química como uma disciplina fundamental da aprendizagem, um fator muito importante para o desenvolver de novos projetos envolvendo essa ciência.

Pergunta 02 (P): Como você visualiza o Jogo Didático no ensino de Química?

Figura 05: Resposta da $P_{2}$ antes da intervenção (Fonte: Própria)

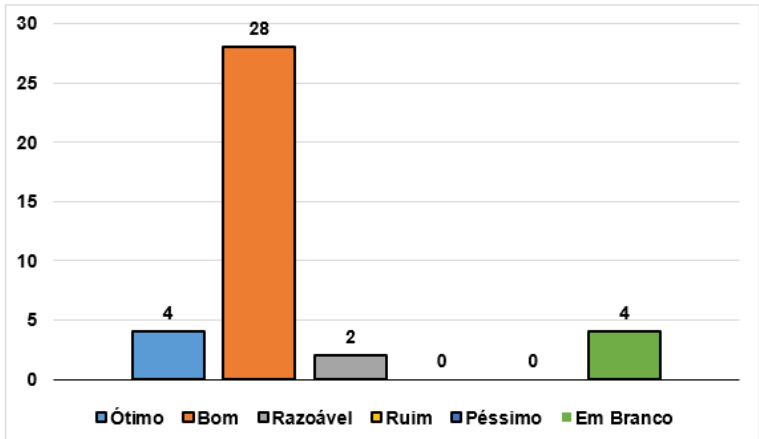

Sendo assim, ao visualizarmos a figura 05 é possível analisar uma curiosidade dos alunos para que o ensino de química seja administrado de maneira mais inovadora, uma vez que, na maioria dos casos os discentes são acostumados com professores utilizando prática tradicional. 
Pergunta $03\left(\mathbf{P}_{3}\right)$ : Ao formar ligações covalentes com Hidrogênio, a eletrosfera do Silício adquire configuração de gás nobre. Com isso, é de se esperar a formação da molécula:
a) $\mathrm{SiH}$
b) $\mathrm{SiH}_{2}$
c) $\mathrm{SiH}_{3}$
d) $\mathrm{SiH}_{4}$
e) $\mathrm{SiH}_{5}$

Figura 06: Resposta da $P_{3}$ antes da intervenção (Fonte: Própria)

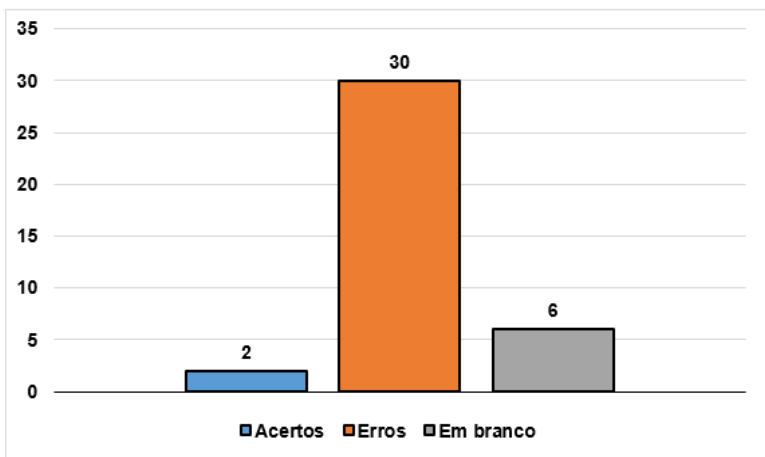

Ao responderem essa questão, pode-se observar na figura 06, foi notado um déficit na aprendizagem, pois dos alunos que responderam, apenas 02 (duas) conseguiram chegar na alternativa correta, enquanto 30 (trinta) erraram e 06 (seis) deixaram em branco. Com isso, foi notado um desafio que deveríamos driblar, no momento em que o jogo fosse posto em prática. Pergunta 04 (P4): O elemento “A” possui número atômico igual a 6, enquanto o elemento "B" possui número atômico igual a 8 . A molécula que representa corretamente o composto formado por esses dois elementos é:
a) $\mathrm{AB}$
b) $\mathbf{B A}$
c) $\mathbf{A}_{2} B$
d) $\mathbf{A B}_{2}$
e) N.D.A

Figura 07: Resposta da $P_{4}$ antes da intervenção (Fonte: Própria)

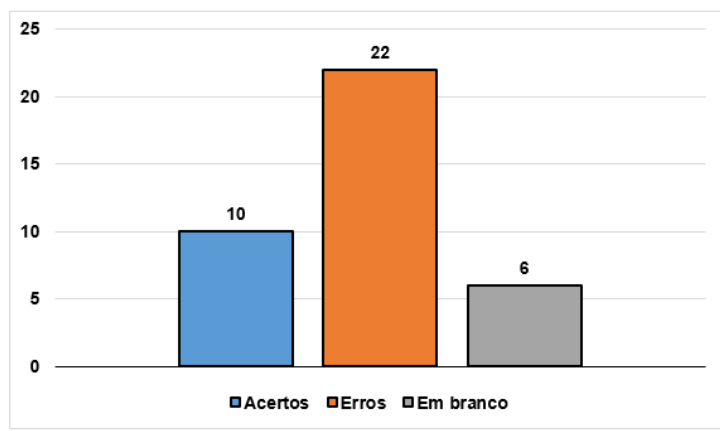


Com os resultados obtidos, observou-se que 10 (dez) alunos acertaram, 22 (vinte e dois) erraram, enquanto 06 (deis) deixaram em branco. Desta maneira, foi analisado que os discentes estavam com sérias dificuldades no assunto de ligações covalentes, visto que o professor responsável pela turma já tinha administrado o assunto, de método apenas teórico.

Pergunta 05 (P5): Determine a fórmula eletrônica e estrutural do seguinte composto $\left(\mathrm{CO}_{2}-\right.$ Dióxido de Carbono):

Figura 08: Resposta da $P_{5}$ antes da intervenção (Fonte: Própria)

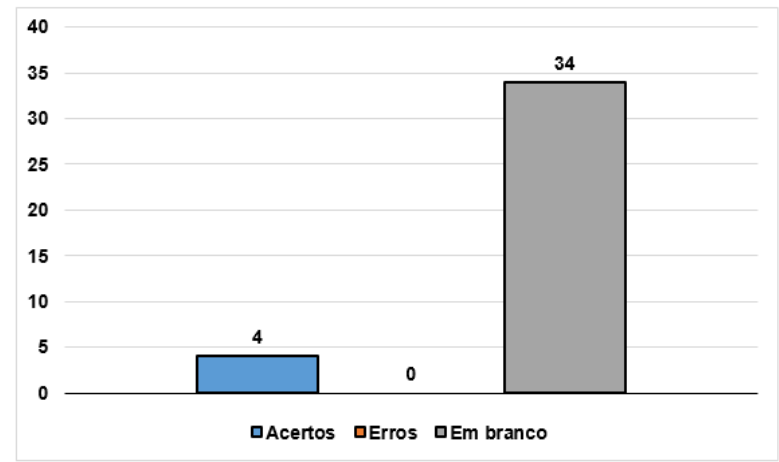

Essa questão apresenta um ponto importante referente ao conteúdo de ligações covalentes, que é determinar se o composto é covalente ou iônico, dessa forma apenas 04 (quarto) estudantes acertaram, 34 (trinta e quarto) deixaram em branco, ou seja, a partir dessa análise, pode-se detectar que os estudantes não haviam domínio no conteúdo específico. Nas figuras abaixo frisamos a resposta de dois estudantes (A e B) para confirmação da resolução segundo Fonseca (2012).

Figura 09: Resposta da $P_{5}$ pelo estudante A (Fonte: Própria)

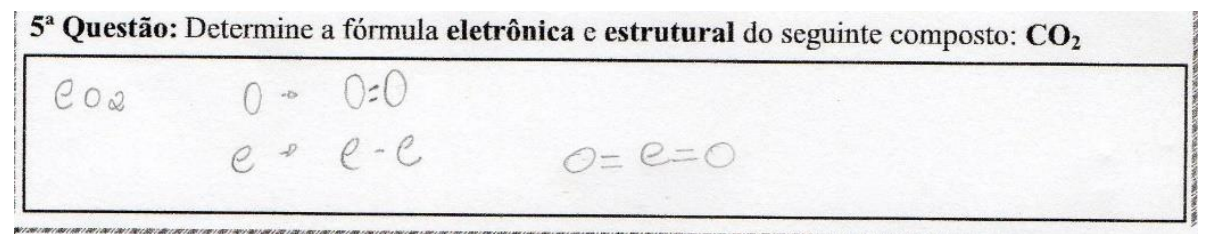

Figura 10: Resposta da $P_{5}$ pelo estudante $B$ (Fonte: Própria)

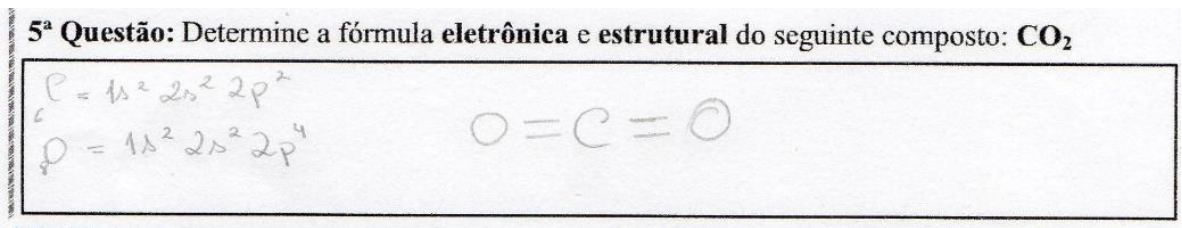

Para resolução da questão P5 utilizamos as contribuições de Fonseca (2012), onde a explicação está na figura 11. "Quando dois átomos estabelecem entre si duas ligações covalentes comuns, forma-se uma ligação dupla. A molécula de $\mathrm{CO}_{2}(\mathrm{~g})$ possui duas ligações 
NASCIMENTO, A. M. S. et al.

duplas. Os pares de elétrons que não estão sendo compartilhados não precisam ser necessariamente representados na fórmula estrutural, logo a fórmula $O=C=O$ também é válida".

Figura 11: Resolução da $P_{5}$ (Fonte: Fonseca, 2012)

\begin{tabular}{|c|c|c|c|c|}
\hline \multicolumn{5}{|c|}{ Molécula de gás carbônico } \\
\hline $\begin{array}{c}\text { Configuração } \\
\text { eletrônica }\end{array}$ & Para completar o octeto: & $\begin{array}{l}\text { Fórmula } \\
\text { molecular }\end{array}$ & Fórmula eletrônica & Fórmula estrutural \\
\hline${ }_{6} \mathrm{C}: 1 \mathrm{~s}^{2} \mathbf{2 s ^ { 2 }} \mathbf{2} \mathrm{p}^{2}$ & $\begin{array}{l}\text { precisa de mais } 4 \text { elétrons. } \\
{ }_{10} \mathrm{Ne}: 1 s^{2} 2 s^{2} 2 p^{6}\end{array}$ & $\mathrm{CO}_{2}$ & $\because \ddot{\circ}:+\dot{c} \bullet+: \dot{\circ} \longrightarrow$ & $\mathrm{O}=\mathrm{c}=\mathrm{O}$ \\
\hline${ }_{8} \mathrm{O}: 1 s^{2} \mathbf{2} \mathbf{s}^{2} \mathbf{2} \mathbf{p}^{4}$ & $\begin{array}{l}\text { precisa de mais } 2 \text { elétrons. } \\
{ }_{10} \mathrm{Ne}: 1 s^{2} 2 s^{2} 2 p^{6}\end{array}$ & & & $\begin{array}{l}\text { também é usual. } \\
\therefore \circ=\mathrm{C}=\dot{\circ}\end{array}$ \\
\hline
\end{tabular}

\section{Segunda Etapa do Ciclo da Experiência - (Investimento)}

Nesse momento, foi apresentada uma aula dialogada por meio de slides sobre o assunto de Ligações Covalentes onde introduzimos alguns conceitos básicos referentes ao respectivo tema, como por exemplo, a Regra do Octeto, bem como exceções a esta regra, princípios para a estabilidade, como se dá o compartilhamento de elétrons e de que forma os mesmos se relacionam com os tipos de ligações formadas.

A partir disso, explicamos o conceito de ligações covalentes: É o compartilhamos de elétrons", citamos alguns exemplos de ligações covalentes com a respectiva estrutura de Lewis por exemplo: " $\mathrm{CH}_{4}, \mathrm{H}_{2} \mathrm{O}, \mathrm{NH}_{3}, \mathrm{CO}_{2}$ e etc", e a Regra do Octeto.

$\mathrm{Na}$ natureza, os únicos elementos cujos átomos são estáveis na forma isolada são os gases nobres. Como todas as propriedades químicas dos elementos estão relacionadas às suas configurações eletrônicas, os cientistas concluíram que a estabilidade dos gases nobres estava relacionada ao fato de os átomos desses elementos possuírem o último nível de energia (camada de valência) completo no estado fundamental. Isso significa ter 02 (dois) elétrons quando a camada de valência for o $1^{\circ}$ nível de energia, e 08 (oito) elétrons quando for o $2^{\circ}, 3^{\circ}, 4^{\circ}, 5^{\circ}$ ou $6^{\circ}$ nível de energia (para os elementos químicos conhecidos).

Essa ideia foi enunciada pela primeira vez em 1916 pelo químico alemão Walther Kossel (1888-1956) como teoria eletrônica de valência e, mais tarde, aperfeiçoada, independentemente, pelos químicos norte-americanos Gilbert Newton Lewis (1875-1946) e Irving Langmuir (1881-1957), que foi quem criou o nome Regra do Octeto. Os átomos dos diferentes elementos estabelecem ligações, doando, recebendo ou compartilhando elétrons para adquirir uma configuração eletrônica igual à de um gás nobre no estado funda 
mental: 8 elétrons no nível de energia mais externo ou, então, 2 elétrons se o nível mais externo for o primeiro. É importante observar, porém, que a regra do octeto é apenas uma "ferramenta" útil para encontrar teoricamente a fórmula dos compostos mais comuns formados por ele mentos representativos (não todos), mas essa regra não explica o fenômeno das ligações químicas e não é seguida pela maioria dos elementos da tabela periódica.

\section{Terceira Etapa do Ciclo da Experiência - (Encontro)}

Nesse momento, foi apresentado aos estudantes à realização e aplicação do jogo "Ludo das Ligações Químicas”. Instruímos os estudantes como jogar, lemos toda a regra do jogo e realizamos uma simulação de como seria o jogo, e pedimos que os mesmos observassem o que acontecia.

Com esse jogo didático, foi possível identificar que os estudantes interagiram fortemente entre si, havendo competição, cooperação, interesse, motivação, divisão, aprendizado. Os estudantes disseram que com o jogo ficou mais divertido aprender a diferenciar os tipos de ligações químicas, que a ligação covalente está presente no jogo, e com isso ficou visível o envolvimento e a motivação dos estudantes na construção do conhecimento.

Para Piaget (1972) interesse e curiosidade fazem parte dos mecanismos de aprendizagem, através das estruturas de assimilação e de acomodação, ou seja, o interesse precede a assimilação. $\mathrm{O}$ autor distingue a curiosidade do interesse, considerando a primeira como um aspecto da acomodação e o segundo, como um aspecto da assimilação.

Para Bruner (1969), o interesse, expresso através da curiosidade é um elemento gerador da aprendizagem, desde que se permita ao sujeito uma análise profunda do conceito. Interesse e curiosidade não são motivos suficientes, mas são grandes oportunidades para o aprendizado.

Figura 12: Terceira Etapa do CEK (Encontro) - Aplicação do Jogo

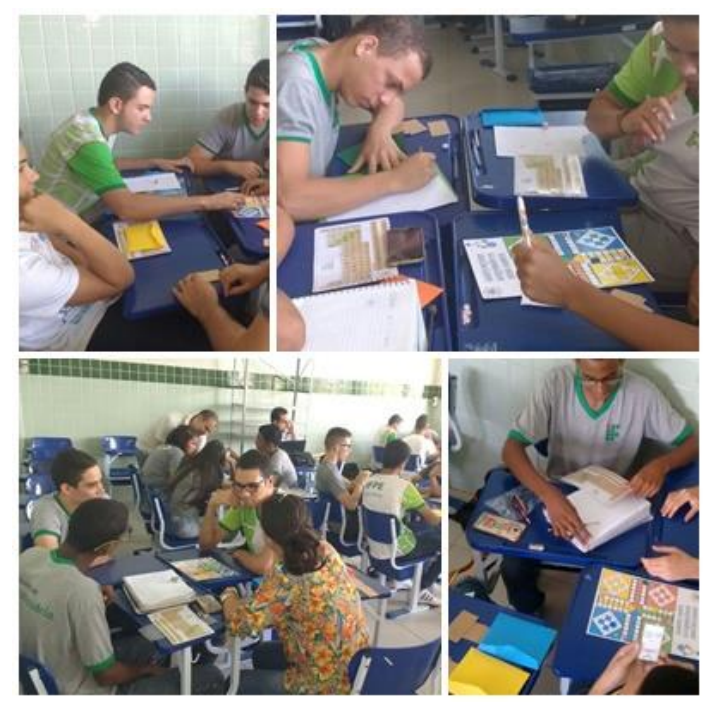

[151] 


\section{Quarta Etapa do Ciclo da Experiência - (Confirmação ou Desconfirmação)}

No transcorrer dessa etapa, fizemos as seguintes perguntas aos estudantes: " $O$ que é Ligação Covalente?", "Cite um exemplo de um composto covalente”, "Faça a fórmula eletrônica e estrutural da $\mathrm{H}_{2} \mathrm{O}$. Através desses questionamentos percebemos que alguns estudantes aprimoraram o que sabiam, pois antes associavam a ligação covalente com a união de dois átomos e esquecendo a valência dos elementos, com isso, sairia incorreto, e depois desta intervenção, a explicação modificaram seus conceitos.

Destacamos aqui algumas respostas dos estudantes que afirmam compreensão do conteúdo com a utilização deste recurso:

Estudante X: "É compartilhamento de pares de elétrons entre átomos".

Estudante Y: “CO2, NH3, H2SO4”.

Nessa visão, é notório que houve confirmação ou desconfirmação conhecimentos prévios dos estudantes a respeito do conceito de Ligações Covalentes.

Ressaltamos a importância dessa etapa, pois é quando o estudante toma consciência do processo, do que sabia antes e do que aprendeu. Reflete também sobre os erros que cometiam anteriormente e o porquê desses erros.

\section{Quinta Etapa do Ciclo da Experiência - (Revisão Construtiva)}

Após a aplicação do jogo e concomitantemente com a aplicação do segundo questionário, foi percebido um aprendizado significativo, afirmando as ideias elaboradas por Santana (2008, p.4), onde o mesmo diz que o lúdico é um importante instrumento de trabalho no qual o mediador, no caso o professor, deve oferecer possibilidades para a elaboração do conhecimento, respeitando as diversas singularidades. Desta forma de acordo com a análise do questionário $\left(\mathrm{Q}_{2}\right)$ foram obtidos os seguintes resultados:

Pergunta 01 (P1): Depois da aplicação do Jogo Didático (“Ludo das Ligações Químicas”) como você ver a disciplina de Química?

Sendo assim, a utilização do jogo didático foi uma maneira de demonstrar que os discentes podem aprender com um método mais dinâmico e complementador da aula teórica. Dentre esse fator, através da análise dos dados, foi notório observar que não houve rejeição por parte dos estudantes na utilização do jogo, uma vez que, de 38 (trinta e oito) alunos, 32 (trinta e dois) acharam ótimo e 06 (seis) acharam bom. O jogo em si apresenta característica a 
voluntariedade, onde o sujeito tem a livre escolha de decidir, se participa ou rejeita o recurso didático.

Pergunta 02 (P): Como você visualiza o Jogo Didático no Ensino de Química? Mais uma vez, o jogo didático foi considerado como um importante contribuinte no ensino dos conteúdos químicos, obtendo relevância para o ensino-aprendizagem, uma vez que, a utilização desse recurso didático ajuda na socialização entre os discentes, no trabalho coletivo dando ênfase a parte divertida do processo sem esquecer do conteúdo aplicado. Entre o grupo de estudantes, cerca de 28 (vinte e oito) estudantes acharam ótimo o jogo didático, que entre suas falas relataram que caso utilize mais jogos didáticos em sala de aula, iria ajuda-los no rendimento escolar, esse é um desafio de muito profissionais da educação que muitas vezes não são capacitados para utilizarem este tipo de recurso.

Pergunta 03 (P): O Jogo Didático (“Ludo das Ligações Químicas”) apresentou uma melhora na sua Aprendizagem? Justifique o que você não sabia, e o que aprendeu após a aplicação do jogo.

Figura 13: Respostas dos Estudantes (C,D,E,F)(Fonte Própria)

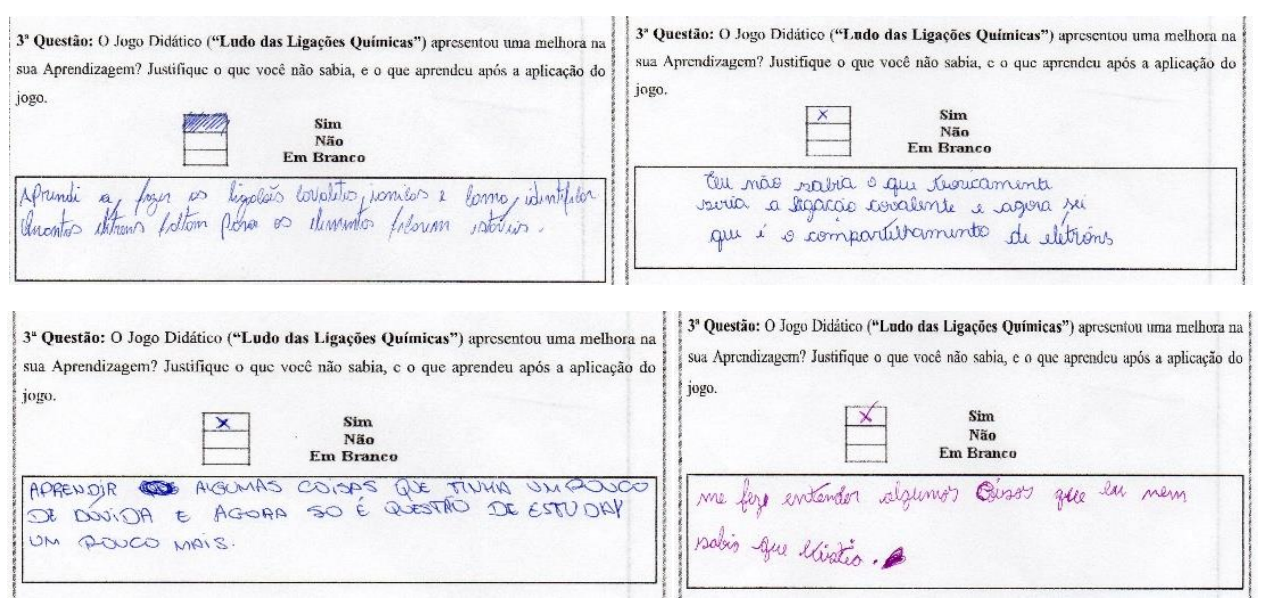

Segundo a figura 13, os relatos dos discentes atribuíram uma importância significativa no jogo aplicado, sendo assim, afirmando que através deste recurso, puderam entender de maneira mais detalhada e divertida o assunto de ligações covalentes.

Pergunta $04\left(\mathbf{P}_{4}\right)$ : Avalie as regras do jogo:

É de suma importância que os alunos deem suas respectivas opiniões quando vão avaliar o jogo didático, pois é uma maneira de contribuir para com o professor, sendo assim, através do parecer do discente, pode ser efetuada determinadas modificações no recurso didático, para que as regras tenham mais clareza no momento de pôr em prática. Com a análise, observou-se 
que cerca da $90 \%$ dos estudantes compreenderam o objetivo do jogo didático.

Pergunta 05 (P5): Ao formar ligações covalentes com o Hidrogênio, a eletrosfera do Silício adquire configuração de gás nobre. Com isso, é de se esperar a formação da molécula:
a) $\mathrm{SiH}$
b) $\mathrm{SiH}_{2}$
c) $\mathrm{SiH}_{3}$
d) $\mathrm{SiH}_{4}$
e) $\mathrm{SiH}_{5}$

Ao responderem essa questão, foi obtido que 30 (trinta) alunos conseguiram acertar e associar as ligações covalentes entre Si e H com a configuração de gás nobre, enquanto que 08 (oito) não fizeram essa associação, sendo assim, marcando resposta diferente da letra $\mathrm{D}$, ou seja, obtiveram erro. Cerca de $62 \%$ dos estudantes conseguiram acerta $\mathrm{P}_{5}$, comparando com a $\mathrm{P}_{4}$ do $\mathrm{Q}_{1}$ que cerca de $26 \%$ dos estudantes acertaram, podemos afirmar que o jogo "Ludo das Ligações Químicas" contribuiu para a aprendizagem dos estudantes.

Pergun ta 06 (P6): O elemento "A" possui número atômico igual a 6 , enquanto o elemento "B" possui número atômico igual a 8 . A molécula que representa corretamente o composto formado por esses dois elementos é:
a) $\mathrm{AB}$
b) $\mathbf{B A}$
c) $\mathrm{A}_{2} \mathrm{~B}$
d) $\mathbf{A B}_{2}$
e) N.D.A

Com os resultados obtidos, foi possível analisar que 26 (vinte e seis) dos alunos conseguiram êxito ao responderem, enquanto que 12 (doze) não conseguiram associar a questão correta.

Pergunta $07\left(\mathbf{P}_{7}\right)$ : Determine a fórmula eletrônica e estrutural do seguinte composto $\left(\mathrm{CO}_{2}-\right.$ Dióxido de Carbono):

Esta última, se tratava de uma questão aberta, onde os alunos deveriam mostrar no papel a ligação entre os componentes dessa molécula, e dos 38 (trinta e oito) alunos, 24 (vinte e quarto) conseguiram realizar de maneira correta, 10 (dez) não conseguiram chegar a resposta devida e 04 (quarto) preferiram deixar em branco. Abaixo na figura 13 mostra algumas respostas selecionadas de 03 (três) estudantes $(\mathrm{G}, \mathrm{H}, \mathrm{I})$ comparando com a resolução da figura 11, baseado no estudo de Fonseca (2012). 
Figura 13: Respostas de 03 (três) estudantes (G, H, I) (Fonte Própria)

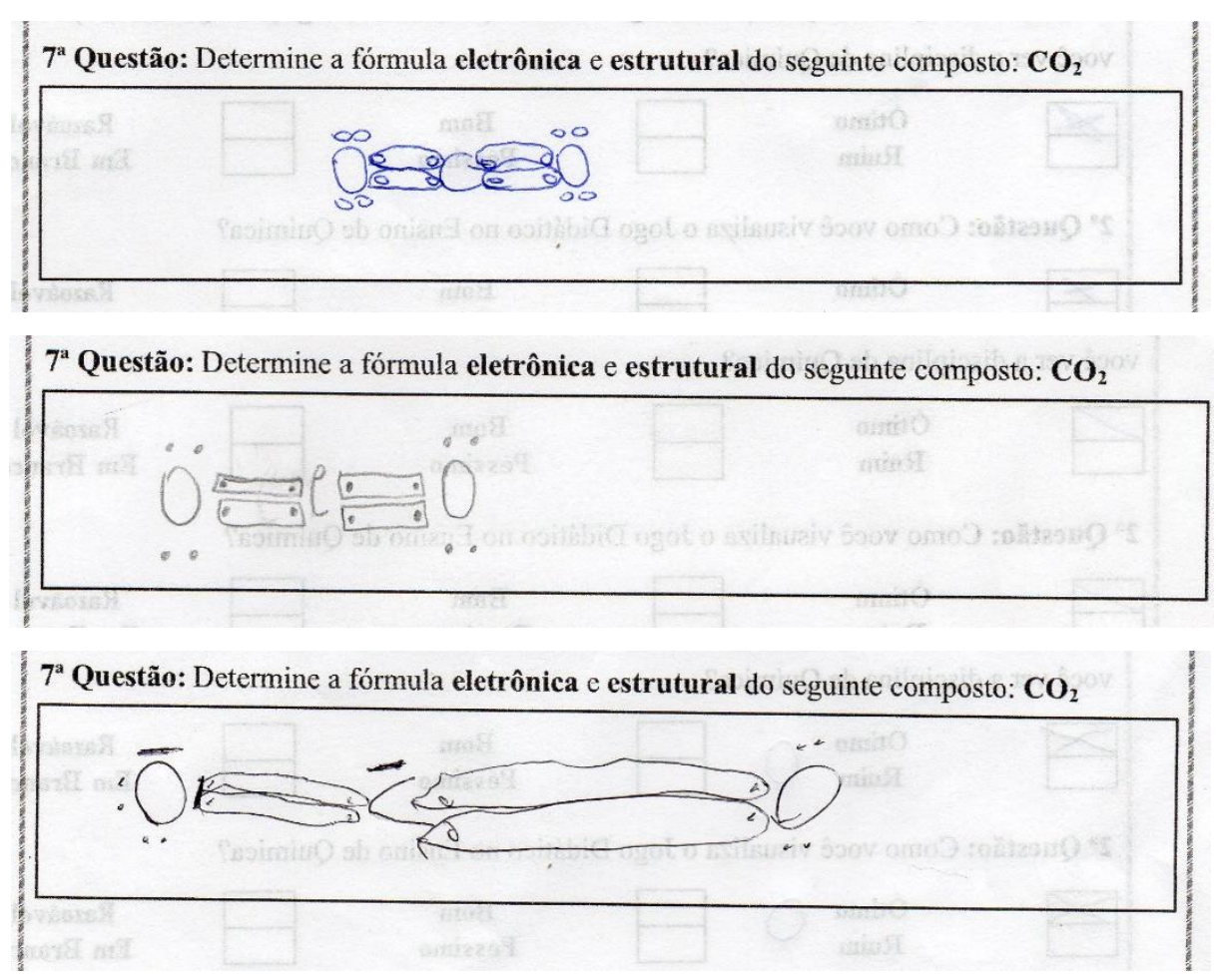

\section{CONSIDERAÇÕES FINAIS}

Após todos resultados obtidos, foi notório o quão importante é a utilização dos jogos didáticos no processo de ensino-aprendizagem, pois na utilização desse recurso, alunos e professores podem interagir de maneira positiva e construtiva, onde o discente se sente mais confortável para fazer questionamentos e tirar dúvidas ao professor, atitudes essas pouco recorrente nas aulas ministradas de maneira tradicional, cujo o aluno é apenas o ouvinte enquanto o professor é o falante.

Analisamos também que na quarta etapa, os estudantes puderam rever suas hipóteses e modifica-las, havendo assim uma evolução do que pensavam antes em relação ao que pensavam depois, como nos exemplos do cotidiano, pois, antes eles não conseguiam relacioná-los, porém depois de se engajar no ciclo foram capazes de reconhecer, podendo sedimentar seus conhecimentos na quinta etapa.

A função educativa do jogo foi facilmente observada durante sua aplicação com os estudantes da escola pesquisada, verificando-se que ela favorece a aquisição e retenção de conhecimentos, em clima de alegria e prazer. Assim, por aliar os aspectos lúdicos aos cognitivos, entendemos que o jogo é uma importante estratégia para o ensino e a aprendizagem de conceitos abstratos e complexos, favorecendo a motivação interna, o raciocínio, a argumentação, a interação entre estudantes e entre professores e estudantes.

Como nos lembra essa autora (Kishimoto, 1996, p.37): “A utilização do jogo 
potencializa a exploração e a construção do conhecimento, por contar com a motivação interna típica do lúdico", e, como disseram alguns dos estudantes: "com o jogo, a gente aprende brincando".

Entretanto é preciso considerar que os jogos didáticos são ferramentas auxiliares ao trabalho de sala de aula e devem ser cuidadosamente avaliados e adequados as situações de ensino. A mera utilização de um jogo didático não garante a aprendizagem do estudante. $\mathrm{O}$ jogo deve ter uma boa qualidade e sobretudo deve ser utilizado no momento certo. Em síntese, jamais se deve fazer uso de qualquer recurso didático sem um rigoroso e cuidadoso planejamento.

\section{REFERENCIAS}

BASTOS, H. F. B. N. Changing teachers' practice: towards a constructivist methodology of physics teaching. 1992. 438 p. Thesis (Doctoral - Philosophy) - Department of Educational Studies, University of Surrey, Guildford, 1992.BRUNER, J.; Uma nova teoria de Aprendizagem. Nora Levy Ribeiro, Rio de Janeiro, Bloch Editores, 2a ${ }^{\text {a }}$ Ed., 1969.

CAMPOS, L.M.L. Bortoloto, T.M.; Felício, A.K.C. A Produção de Jogos Didáticos para o Ensino de Ciências e Biologia: Uma Proposta para Favorecer a Aprendizagem, 2003.

FONSECA, M. R. M.; Química (Ensino Médio). 1ª Edição. São Paulo, Editora: Ática, v.1, 2012.

FREITAS, O. Equipamentos e materiais didáticos. Brasília: Universidade de Brasília. 2007. 132p. ISBN: 978-85-230-0979-3, 2007.

KELLY, G. A. A theory of personality: the psychology of personal constructs. New York: W.W. Norton, 1963.

KISHIMOTO, T. M. Jogo, Brinquedo, Brincadeira e a Educação. São Paulo: Cortez, 1996. $183 \mathrm{p}$.

KISHIMOTO, T. M. Jogo, brinquedo e brincadeira. São Paulo: Cortez, 2003.

LARA, Isabel Cristina Machado de. Jogando com a Matemática de $5^{\mathbf{a}}$ a $8^{\mathbf{a}}$ série. São Paulo: Rêspel, 2004.

LIBÂNEO, J. C. Didática. São Paulo: Cortez, 1994. $2^{\circ}$ edição.

LUCK, H. Pedagogia interdisciplinar: fundamentos teórico-metodológicos. Petrópolis: Vozes, 2010.

MIRANDA, S. de. No fascínio do jogo, a alegria de aprender. Ciência hoje. V.28, n. 168. Jan/fev. 2002, p.64-66.

NASCIMENTO, A. M. S. et al. Dados Pauling: Um Jogo Didático no Conteúdo de Distribuição 
Eletrônica no Ensino de Química. In: Atas do Simpósio Brasileiro de Educação Química, 2014.

NASCIMENTO, A. M. S. et al. Dominós das Funções Oxigenadas: Um Jogo Didático no Conteúdo de Química Orgânica. In: Anais do $55^{\circ}$ Congresso Brasileiro de Química, Goiânia GO 2015.

PEDROSO, C.V. Jogos didáticos no ensino de biologia: uma proposta metodológica baseada em módulo didático. Anais do IX Congresso Nacional de Educação. Curitiba, Brasil, 2009.

PERRENOUD, P. Dez novas competências para ensinar. Porto Alegre: Artmed, 2000.

PIAGET, J. Psicologia e Pedagogia. Dirceu Accioly Lindoso, Rio de Janeiro, Cia. Ed. Frense, 1972, p. 160.

SANTANA, E.M.; Rezende, D.B. O Uso de Jogos no ensino e aprendizagem de Química: Uma visão dos alunos do $9^{\circ}$ ano do ensino fundamental. Anais do XIV Encontro Nacional de Ensino de Química. Curitiba, Brasil, 2008.

SILVA, M.A.S et al. Utilização de Recursos Didáticos no processo de ensino e aprendizagem de Ciências Naturais em turmas de $8^{\circ}$ e $9^{\circ}$ anos de uma Escola Pública de Teresina no Piauí. In Anais do VII Congresso Norte Nordeste De Pesquisa E Inovação, Tocantins 2012. 